\title{
Impact of internal variability on climate change for the upcoming decades: analysis of the CanESM2-LE and CESM-LE large ensembles
}

\author{
Gabriel Rondeau-Genesse ${ }^{1}$ (D) $\cdot$ Marco Braun $^{1}$
}

Received: 27 April 2018 / Accepted: 2 September 2019/Published online: 16 September 2019

(C) The Author(s) 2019

\begin{abstract}
The pace of climate change can have a direct impact on the efforts required to adapt. For short timescales, however, this pace can be masked by internal variability (IV). Over a few decades, this can cause climate change effects to exceed what would be expected from the greenhouse gas (GHG) emissions alone or, to the contrary, cause slowdowns or even hiatuses. This phenomenon is difficult to explore using ensembles such as CMIP5, which are composed of multiple climate models and thus combine both IV and inter-model differences. This study instead uses CanESM2LE and CESM-LE, two state-of-the-art large ensembles (LE) that comprise multiple realizations from a single climate model and a single GHG emission scenario, to quantify the relationship between IV and climate change over the next decades in Canada and the USA. The mean annual temperature and the 3-day maximum and minimum temperatures are assessed. Results indicate that under the RCP8.5, temperatures within most of the individual large ensemble members will increase in a roughly linear manner between 2021 and 2060. However, members of the large ensembles in which a slowdown of warming is found during the 2021-2040 period are two to five times more likely to experience a period of very fast warming in the following decades. The opposite scenario, where the changes expected by 2050 would occur early because of IV, remains fairly uncommon for the mean annual temperature, but occurs in 5 to $15 \%$ of the large ensemble members for the temperature extremes.
\end{abstract}

\section{Introduction}

Global temperatures are expected to increase due to the radiative forcing of anthropogenic greenhouse gases (van Vuuren et al. 2011; Collins et al. 2013; Settele et al. 2014). Typically,

Electronic supplementary material The online version of this article (https://doi.org/10.1007/s10584-01902550-2) contains supplementary material, which is available to authorized users.

Gabriel Rondeau-Genesse

rondeau-genesse.gabriel@ouranos.ca 
studies that investigate climate change have done so by examining how certain climatic indices of a future period will differ in comparison with a reference period (Collins et al. 2013). This method has many benefits, the first of which being the simplicity of interpreting the results when presented as a delta compared with the recent past. What this method lacks, however, is a measure of how fast the projected change is expected to be reached. This is crucial information, as the capacity for human and natural systems to adapt to a changing environment is limited by the speed of such change (Settele et al. 2014). Moreover, the planning processes of decision makers are, by definition, continuous processes, which means that climate deltas for future horizons are only of limited use in adaptation planning if the pace of said change is unknown (Klein et al. 2014).

In the last few years, several attempts have been made to circumvent this problem, such as the use of continuous analyses using sequential data over longer periods of time covering both past and future, the time of emergence of the climate change signal, or an estimated timescale before a problematic change occurs (Giorgi and Bi 2009; Hawkins and Sutton 2012; de Elía et al. 2014; Chavaillaz et al. 2016a). Recent studies have suggested that an acceleration of warming is to be expected in the first half of the century if future greenhouse gas (GHG) concentrations develop towards the RCP8.5 GHG emission scenario (Chavaillaz et al. 2016b).

That is not to say that temperatures will increase steadily over time, or that this potential acceleration in warming will be constant. Even within higher GHG emission scenarios, the pace of change for shorter timescales is influenced by internal variability (IV), which dictates that slowdowns, temporary hiatuses, and negative trends can be expected, regardless of the spatial scale (Meehl et al. 2011; de Elía et al. 2013; Deser et al. 2014; Fyfe et al. 2016). As warming accelerates, however, 10- and 20-year cooling trends should become less common or even nonexistent (Grenier et al. 2015; Kay et al. 2015). On the opposite, extremely warm decades or 20-year periods should become more likely to happen (Chavaillaz et al. 2016b). In North America, these phenomena are tied to secondary factors such as the North Atlantic Oscillation (NAO) and the El Niño-Southern Oscillation (ENSO).

Another issue for adequately assessing the pace of climate change is that many of the aforementioned studies that focused on IV have relied on ensembles such as the fifth Coupled Model Intercomparison Project (CMIP5), a multi-model and multi-realization large ensemble (Taylor et al. 2011). By their nature, these ensembles combine IV and inter-model variability caused by differing physics, dynamical cores, and resolutions, which makes it almost impossible to assess the portion of uncertainty caused by IV alone (Kay et al. 2015). In the last few years, two projects have aimed at better understanding internal variability. They consist of single-model large ensembles, respectively run with the Community Earth System Model version 1 coupled with the Community Atmosphere Model version 5 (CESM1(CAM5); Hurrell et al. 2013; Kay et al. 2015) and the Second Generation Canadian Earth System Model (CanESM2; Arora et al. 2011; von Salzen et al. 2013; Sigmond and Fyfe 2016). These large ensembles have the obvious advantage of circumventing inter-model variability.

A study by Sheffield et al. (2013) concluded that while no model stood out as inherently better or worse, CMIP5 models, including CanESM2, represented intraseasonal through multidecadal variability over North America adequately well. This study was done over a variety of phenomena ranging from ENSO to the Pacific decadal oscillation (PDO). In particular, the PDO influences multi-decadal variability and was one of the phenomena that was well reproduced by a majority of models. Those results are also valid for CanESM2-LE and CESM-LE, which were found to adequately reproduce the observed interannual and trend patterns of tropical Pacific precipitation, extratropical sea level pressure and North American 
surface temperature (Sigmond and Fyfe 2016). Other studies also showed that while biases exist, especially in Alaska and Western USA, CESM-LE reproduces the spatial patterns of observed surface air temperature variability (Lehner et al. 2017; McKinnon et al. 2017). Finally, while CanESM2-LE is found to capture most snow-related climate parameters, it overestimates springtime snow mass over Canada and underestimates sea ice (Kushner et al. 2017; Seviour 2017). Based on these validation studies, it can be assumed that the internal variability of both large ensembles can serve as an adequate proxy for the real world natural variability of the near future.

Our capability to mitigate impacts and to adapt to climate change is limited by the pace of said change, which is itself shadowed or intensified by IV for short timescales. In extreme cases, this can mean that long-term trends such as the 2050 horizon could be reached a few decades early if the right conditions meet. In this context, our study aims to use CanESM2-LE and CESM-LE to quantify the impact of IV on the pace of warming in Canada and the United States of America (USA) for the upcoming decades. This will be realized through an analysis of the disparity in short-term trends and variability between individual members of both large ensembles. As it is of importance for climate change adaptation, we also explore the possibility that severe shifts in climate might occur within the constraints of IV. CMIP5 is included in this analysis, as this ensemble is commonly used for climate studies and, therefore, it is relevant to assess how its variability compares with CanESM2-LE and CESM-LE.

\section{Data and study area}

\subsection{Datasets}

\subsubsection{Large ensemble projects}

The two single-model large ensembles (LE) used in this study were produced with the CanESM2 and CESM1(CAM5) global circulation models (GCMs).

CanESM2 is the Second Generation Earth System Model from Environment and Climate Change Canada's (ECCC) Canadian Centre for Climate Modelling and Analysis (CCCma) (Arora et al. 2011; von Salzen et al. 2013). It has a spatial resolution of approximately $2.8^{\circ}$ in latitude and longitude. CESM1(CAM5) is a coupling of the Community Earth System Model version 1 and the Community Atmosphere Model version 5 (Hurrell et al. 2013; Kay et al. 2015). It constitutes a cooperative effort between various US climate research centers, supported by the National Science Foundation (NSF) and centered at the National Center for Atmospheric Research (NCAR). Its resolution is finer than CanESM2, with a grid of approximately $0.94^{\circ}$ in latitude and $1.25^{\circ}$ in longitude.

Unlike CMIP5, CanESM2-LE and CESM-LE are produced with a single model, which means that the behaviors and spatial patterns that are observed within their datasets are heavily influenced by the physics of the models themselves. In particular, CanESM2 and CESM1(CAM5) have been found to have an equilibrium climate sensitivity (ECS) that is above the CMIP5 average, which is likely to have an effect on the pace of warming. This metric is used to quantify the model response to an instantaneous doubling of the $\mathrm{CO}_{2}$ concentration. Previous studies that addressed this question have pointed out that the ECS of CMIP5 models ranges from 1.5 to $4.5^{\circ} \mathrm{C}$, while CanESM2 has an ECS of $3.69{ }^{\circ} \mathrm{C}$ and CESM1(CAM5) has an ECS of $4.10^{\circ} \mathrm{C}$ (Meehl et al. 2007, 2013; Andrews et al. 2012). 
CanESM2-LE has 50 members (Sigmond and Fyfe 2016), whereas CESM-LE consists of 40 members (Kay et al. 2015). At the time of this study, only 30 members were available. Both large ensembles are created in a similar manner: CMIP5 historical forcings are used before 2005 and small random atmospheric perturbations are applied in around 1920 to trigger multiple members. In both cases, the RCP8.5 is used from 2006 and onwards (Kay et al. 2015; Sigmond and Fyfe 2016). All data was used at a daily time step.

\subsubsection{CMIP5}

CMIP5 is an ensemble of opportunity commonly used in climate research, as it encompasses all three major sources of uncertainties: future GHG emissions, internal variability, and model inaccuracies (Hawkins and Sutton 2009; Taylor et al. 2011). However, since only a limited number of models provide multiple runs, it is difficult to assess IV and distinguish it from inter-model variability. In this regard, it is relevant to assess how the variability of a CMIP5 ensemble compares with the IV-focused CanESM2-LE and CESM-LE.

Only CMIP5 models with daily RCP8.5 data were retained, since this corresponds to CanESM2-LE and CESM-LE data. When more than one member realization was available for a CMIP5 model, the first one was chosen. In total, 28 CMIP5 models were used. They are listed in Online Resource 1.

\subsection{Climate indices}

As a baseline, the pace of warming is explored with the use of the annual average surface air temperature (Tmean). We also assess how internal variability can impact the 3 hottest consecutive days per year (TX3day), as heat stress is a leading cause of weather-related human mortality (Meehl and Tebaldi 2004; Guirguis et al. 2014). In a similar fashion, the 3 coldest consecutive days per year (TN3day) can inform on events such as cold waves in Canada and northern USA.

Further validation of the large ensembles based on those climate indices was accomplished and is in accordance with the existing literature cited in section 1. While biases do exist in CanESM2-LE and CESM-LE, both ensembles are able to adequately capture the spatial patterns of interannual variability for all three climate indices, as described by the Daymet Version 3.0 observed dataset (Thornton et al. 2016) for the 1980-2017 period. In particular, both ensembles overestimate the interannual variability in Alaska and western Canada for all three indices, as well as in the Canadian Arctic for both extreme indices. Furthermore, some overestimation can be observed throughout Canada (TX3day and TN3day) and the East Coast (TX3day only) with CanESM2, while CESM-LE performs adequately for the rest of the domain with the exception of the southern Great Plains (discussed in section 3.2). Figures are available in Online Resource 2 and 3.

\subsection{Study area}

This study was realized with a focus on Canada and the USA, which we limited by latitudes $25^{\circ} \mathrm{N}$ and $80^{\circ} \mathrm{N}$, and by longitudes $50^{\circ} \mathrm{W}$ and $165^{\circ} \mathrm{W}$. Only grid cells with a land fraction higher than $50 \%$ were retained for the analysis. 


\subsection{Pace and severity of short-term climate change}

We define time periods as:

$$
t=Y \pm{ }^{n} / 2
$$

where $Y$ is the year located at the center of an $n$-year period. The value of change between two time periods is defined as:

$$
\Delta T_{Y_{2} / Y_{1}}=\langle T\rangle_{t_{2}}-\langle T\rangle_{t_{1}}\left[{ }^{\circ} \mathrm{C}\right]
$$

where $\langle T\rangle_{t}$ is the temporal average of a given index $\left({ }^{\circ} \mathrm{C}\right)$ within time periods $t_{1}$ and $t_{2}$. When two time periods are consecutive, $\Delta T$ provides information on the pace of warming.

As climate changes over the next century, it is reasonable to anticipate that humans will adapt many of their activities to the new day-to-day reality (Settele et al. 2014; Chavaillaz et al. 2016b). The characterization of a warm or cold year will evolve according to recent climate (Moore et al. 2019). Thus, it is of interest to qualify the severity of the upcoming changes in relation to the recent past, to characterize the "departure from normal" of the upcoming climate in a similar way to a signal-to-noise ratio. This is accomplished through the use of the interannual variability during time period $t_{1}$. The severity of the change can be defined as:

$$
\alpha_{Y_{2} / Y_{1}}=\frac{\Delta T_{Y_{2} / Y_{1}}}{\sigma_{T Y_{1}}}
$$

where $\sigma_{T Y_{1}}$ is the interannual standard deviation during time period $t_{1}$, and $\alpha_{Y_{2} / Y_{1}}$ represents the departure from normal, in standard deviations $(\sigma)$, between the two time periods. For example, Chavaillaz et al. (2016b) used this severity index to locate regions exposed to fast increases in temperature (labeled extremely warm years) based on $\alpha$ values of $2 \sigma$ or more between two consecutive 20-year periods. Another study, by de Elía et al. (2014), used a similar factor to account for the vulnerability of end users in regard to the timescale of climate change.

In our study, $\alpha_{Y_{2} / Y_{1}}$ is calculated for individual large ensemble members. Within a given grid cell, the probability for the ensemble to surpass a given threshold can be expressed as:

$$
P=\left(\sum_{i=1}^{m} \delta_{\varphi i} / m\right) \cdot 100 \quad[0-100 \%]
$$

where $m$ corresponds to the number of members within the large ensemble and where $\delta_{\varphi i}$ is equal to:

$$
\delta_{\varphi i}= \begin{cases}1 & \text { if } \alpha_{Y_{2} / Y_{1}} \geq \varphi \\ 0 & \text { if } \alpha_{Y_{2} / Y_{1}}<\varphi\end{cases}
$$

where $\varphi$ is a signal-to-noise threshold.

\section{Results}

\subsection{Single grid cell-20-year running baseline}

The severity of change, as defined by Eq. 3, is constructed by two parameters: the multidecadal variation, $\Delta T_{Y_{2} / Y_{1}}$, which represents the scale of changing climate between two time 
periods, and the interannual variability of the recent past $\sigma_{T Y_{1}}$, which is calculated for the first time period. As a first analysis, these two parameters are examined separately. A baseline of 20 years was deemed adequate for our study, since this timeframe is close to the planning cycle of decision-makers while still providing statistical accuracy (Liebmann et al. 2010). The parameters $t_{1}$ and $t_{2}$ are thus defined as two consecutive 20-year periods between 1971 and 2099 and used to compute $\Delta T_{Y_{2} / Y_{1}}$. As an example, for the first delta, $t_{1}$ is defined as 19711990 and $t_{2}$ as 1991-2010. For the 2nd delta, $t_{1}$ is defined as 1972-1991 and $t_{2}$ as 1992-2011, and so on. This analysis makes it possible to examine how the change from one 20-year period to the following one evolves throughout the twenty-first century. Figure 1 presents data extracted at the grid cell closest to Montreal (QC, Canada). As a general note, it can be mentioned that many other grid cells share an appearance similar to Fig. 1, and that regional patterns are discussed in later sections. To complement this information, similar figures for the grid cells over Resolute (NU, Canada) and Miami (FL, USA) are provided in Online Resources 4 and 5. They respectively represent regions subject to a strong climate change signal and to a low interannual variability.

Despite CanESM2-LE and CESM-LE being single-model large ensembles and CMIP5 being an ensemble of opportunity, the spread between members for $\Delta T$ and $\sigma_{T}$ is of the same order of magnitude for all three datasets. This is corroborated by Kay et al. (2015), who noted that the spread of trends in North America generated by the internal climate variability of CESM-LE was often statistically indistinguishable from CMIP5. This observation was made for winter surface air temperature but appears to be equally valid for our climate indices. One notable exception is TX3day derived from CESM-LE, where the spread between members is minimal. This has been observed on a majority of grid cells on the East Coast, including Miami (Online Resource 5).

On average, $\sigma_{T}$ appears stable throughout the century, although a slow drift upwards or downwards can sometimes be observed. Most notable, with TN3day-CanESM2-LE, is that $\sigma_{T}$

a) CanESM2-LE
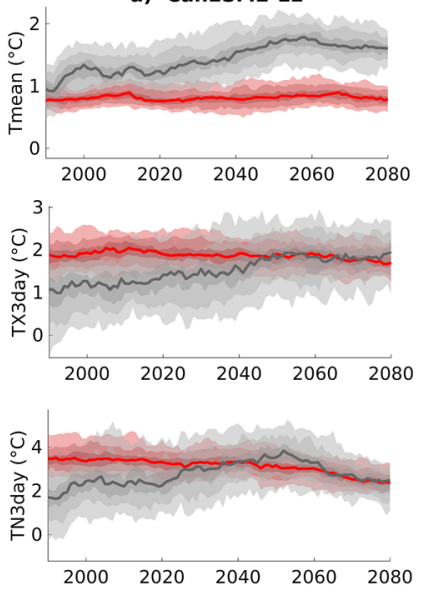

b) CESM-LE
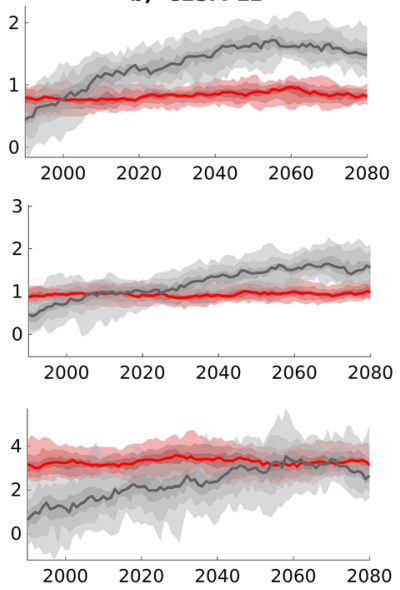

c) CMIP5
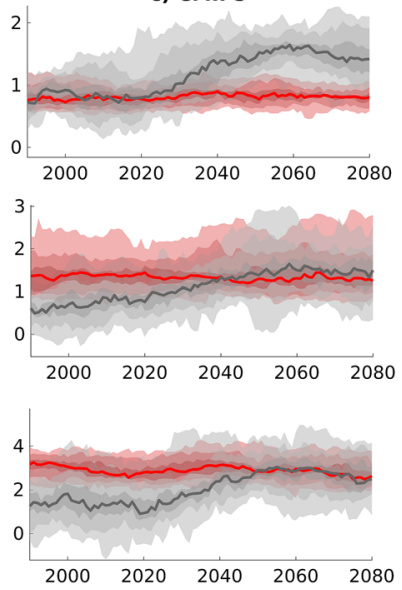

Fig. 1 Magnitude of warming ( $\Delta T$, gray), calculated between two consecutive 20 -year periods, and the interannual variability of the first 20-year period $\left(\sigma_{T}\right.$, red). Data in the figure corresponds to the grid cell closest to Montreal (Canada). The years on the $x$-axis correspond to the midpoint of the two 20-year periods (i.e., 2020 for 2021-2040 vs. 2001-2020). Columns of graphs correspond to the three datasets (CanESM2-LE, CESM-LE, and CMIP5). Rows correspond to the three temperature indices. The line represents the median of the ensemble, whereas the shades of color correspond to the 66th (33rd), 85th (15th), and 95th (5th) percentiles 
steadily decreases over time, while no such behavior is reproduced by CESM-LE or CMIP5. Further research would be needed to fully explain that behavior, but an early hypothesis is that this decrease in interannual variability could be linked to a loss in snow cover, which is found to be more pronounced in CanESM2-LE compared with CMIP5 (Lin and Wu 2011; Mote and Kutney 2012; Gastineau et al. 2017; Mudryk et al. 2018).

For most indices, a plateau or a slight slowdown of warming $(\Delta T)$ can be observed from the 2050s onwards. This is in concordance with Chavaillaz et al. (2016b), who noted that the maximum extent of extremely warm years occurred around 2060 with the RCP8.5 and CMIP5 data. It is to be reaffirmed that this plateau affects the pace of warming, not the temperature themselves. Average temperatures at the end of the century are rising at a median rate of approximately $1.5^{\circ} \mathrm{C} / 20$ years, which is much faster than at the start of the century.

\subsection{Average pace of warming-2001-2060}

The year or period around 2050 has often been used as a future horizon in climate studies, as it marks the midpoint in the century and corresponds to life cycles of major infrastructure investments. Thus, using consecutive 20-year periods, we focus the rest of the study on the "path" that climate might take to reach that period. Figure 2 illustrates the normalized pace of change $\alpha_{2030 / 2010}$ and $\alpha_{2050 / 2030}$, averaged over the large ensemble members.

For the most part, Fig. 2 confirms the assertion discussed in section 3.1 that CanESM2-LE, CESM-LE, and CMIP5 indicate a similar warming and interannual variability. Being an ensemble of opportunity, however, spatial patterns and values of change in CMIP5 tend to be smoothed out due to model differences. On the contrary, CanESM2-LE and CESM-LE keep the same physics across all members, i.e., the underlying hypotheses and algorithms that dictate the model's behavior do not change. This is likely the reason why spatial patterns are more defined. As discussed previously, CESM1(CAM5) has been found to have a high climate sensitivity (Meehl et al. 2013). As a result and despite the 30 members of the ensemble, TX3day in the Arctic region warms at average paces in the 1.7 to $2.0 \sigma$ range, compared with 0.5 to $1.0 \sigma$ with CMIP5 and CanESM2-LE.

Another notable spatial feature is the circle of low signal-to-noise ratios observed in central USA with TX3day-CESM-LE. To better illustrate the causes behind the low pace

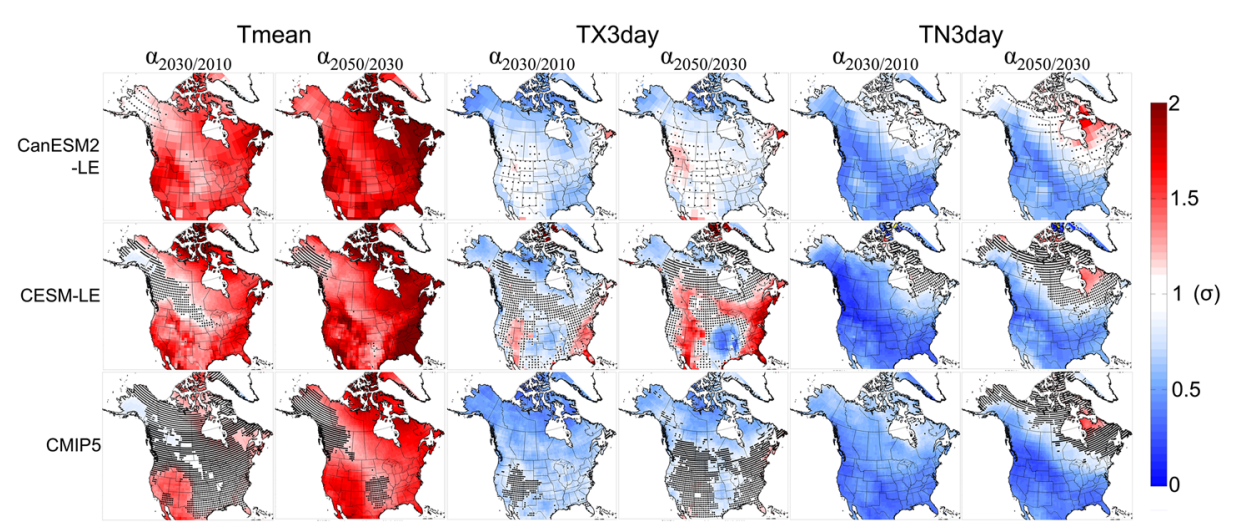

Fig. 2 Average normalized shift $(\sigma)$ between the 2001-2020, 2021-2040, and 2041-2060 temperatures. The subscripts to $\alpha$ indicate the midpoint of the 20-year period being considered. The dotted areas indicate grid cells, where less than $66 \%$ of the members agree around a signal-to-noise ratio of 1 (defined by $\delta_{1}$-Eq. 5) 
of change in this area, the two main components of $\alpha_{2050 / 2030}, \Delta T_{2050 / 2030}$, and $\sigma_{T 2030}$ are illustrated in Online Resource 6. Despite some local discrepancies, the magnitude of warming $\Delta T_{2050 / 2030}$ is similar in both CanESM2-LE and CESM-LE. A notable exception is an area of fast warming in CESM-LE simulations in the Northern Plains climatic region, as defined by Bukovsky (2011), and an area of high interannual variability throughout the Great Plains. Previous studies have noted strong land-atmosphere interactions in these areas, where summer warming is prone to cause a decrease of soil moisture and, in turn, reduce evaporation and rainfall. A consequence of these phenomena is the creation of warming hotspots, with the strongest effects on temperature extremes (Koster et al. 2004; Seneviratne et al. 2013). CESM-LE has been found to be sensitive to this phenomenon (Merrifield et al. 2017), whereas our results suggest that this is not the case for CanESM2-LE.

With the Tmean and TX3day indices, values for both $\alpha_{2030 / 2010}$ and $\alpha_{2050 / 2030}$ are high on the coasts and can reach upwards to $2 \sigma$. This is due to the lower interannual variability in these areas compared with inland, rather than a higher magnitude of warming $\Delta T_{2050 / 2030}$. In a similar way, for TN3day and all three ensembles, a band of high interannual variability follows the eastern side of the Rocky Mountains from Alaska to south-central USA and causes lower $\alpha$ values in those regions. This has been observed in other studies (Hawkins and Sutton 2012; de Elía et al. 2013; Lehner et al. 2017).

\subsection{Internal variability and the short-term pace of warming}

In recent years, climate studies have started to focus on decadal timescales, to better respond to the planning horizons of decision makers (Hawkins 2011; Klein et al. 2014). However, climate variability is often dominant within those timeframes, which impacts the usefulness of traditional climate change information. In an effort to identify and quantify unexpected events and climate shifts for which stakeholders could find themselves unprepared for, information is extracted from individual large ensemble members to explore the probabilities for warming slowdowns or accelerations.

As an example of such phenomena, Fig. 3a and b illustrate Tmean for members \#10 and \#17 of CanESM2-LE at the grid cell closest to Montreal. In terms of the 2050 horizon, defined as 2041-2060 vs 2001-2020, both members are similar and respectively indicate $\alpha_{2050 / 2010}$ increases of $3.22 \sigma$ and $3.43 \sigma$. However, as is evident on Fig. 3, the path taken by those two members to reach the 2050 horizon is quite different. Looking at the ratio of $\alpha_{2030 / 2010}$ and $\alpha_{2050 / 2010}$ (thereafter noted $R_{2010 / 2050}$ for simplicity), member \#10 (Fig. 3a) barely reaches $22 \%$ of its total increase by the 2021-2040 period, while member \#17 (Fig. 3b) reaches 70\%. This kind of information is often hidden within the time series of continuous ensemble analyses, but would imply drastically different impacts for mid-term timescales, compared with the linear increase suggested by the large ensemble envelope.

The occurrence of low and high ratios, as seen in Fig. 3 a and b, needs to be assessed and compared with what the uncertainty envelope would suggest, which in this case is a mostly linear increase from 2001 to 2060 . Figure 3c presents a schematization of the aggregation of $R_{2010 / 2050}$ within the following categories:

a. $R_{2010 / 2050}<0.35$ comprises cases where the first 20 -year change is either small in comparison with the 40 -year change, null, or negative. (concave arc-accelerating rate of change) 
Fig. 3 Progression of $T$ mean at the Montreal grid cell between 2001 and 2060 for a CanESM2-LE member \#10 and b CanESM2-LE member \#17. The dotted lines represent the average for each of the 20-year periods; the shaded area represents the interannual standard deviation. c Schematization of the ratio between the 20-year change and the 40-year change $\left(R_{2010 / 2050}\right)$, using 2000-2021 as reference. The ratio $R_{2010 / 2050}$ for all 50 CanESM2-LE members was classified into three categories: $R_{2010 / 2050}<0.35$ (accelerating rate of change - concave arc), $R_{2010}$ / ${ }_{2050} \approx 0.50$ (linear change), and $R_{2010 / 2050}>0.65$ (decelerating rate of change - convex arc). Line width represents the percentage of members within a particular category a)

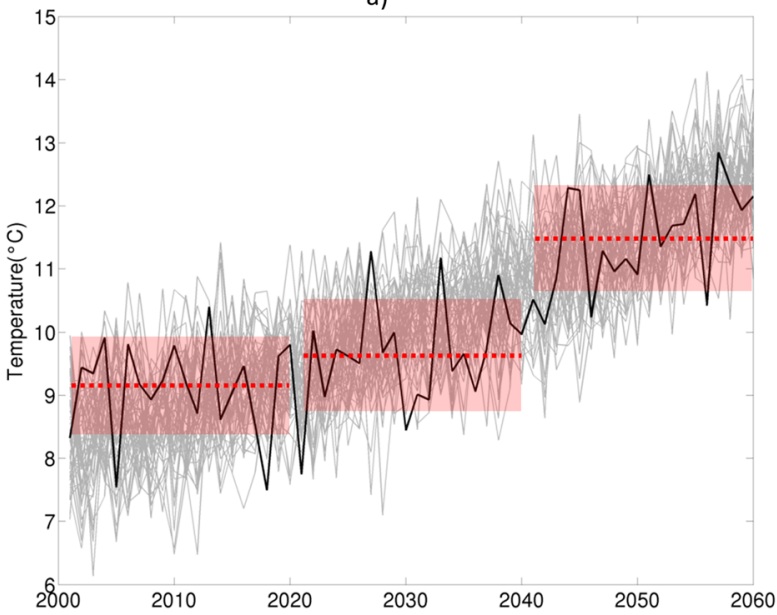

b)

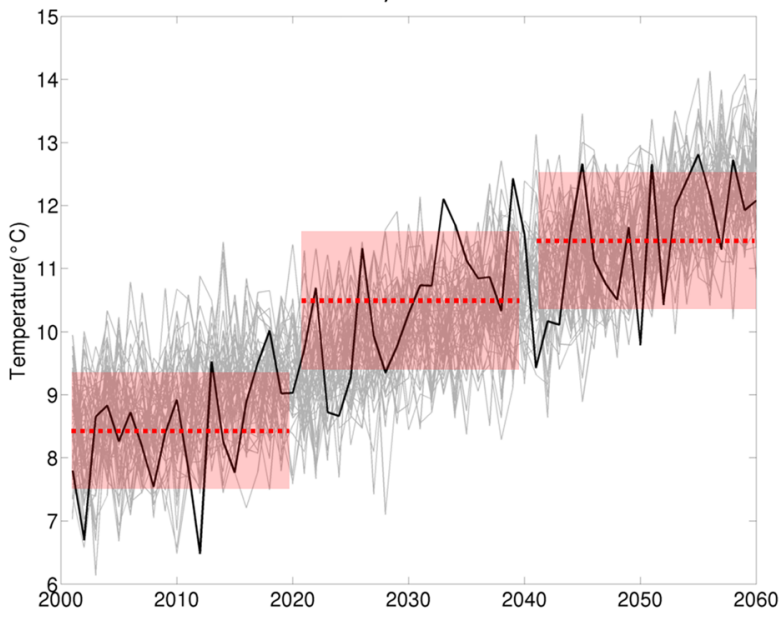

c)

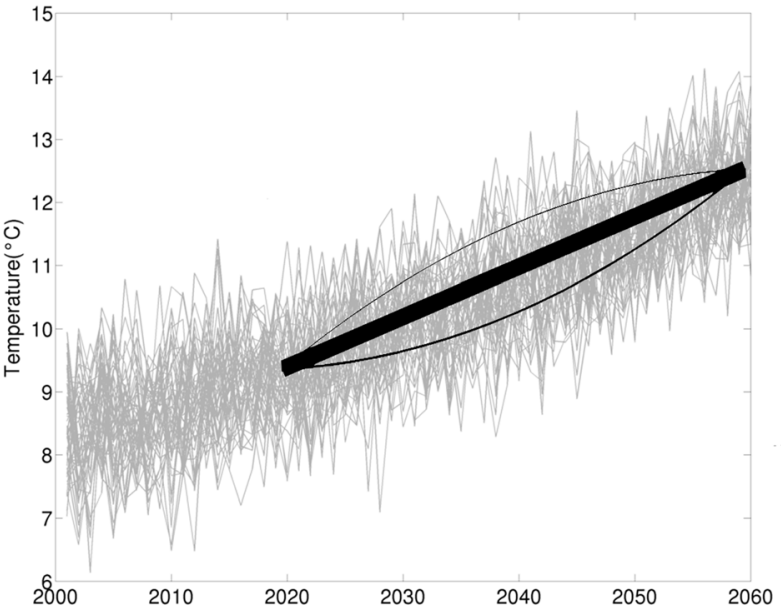


Fig. 4 Distribution of the pace of warming within ensemble members between 2001 and 2060, classified into 3 categories based on the $\alpha_{2030 / 2010} / \alpha_{2050 / 2010}$ ratio $\left(R_{2010 / 2050}\right)$. Only simulations with $\alpha_{2050 / 2010}>1$ were categorized. The fraction of simulations with a change signal $\alpha_{2050 / 2010}<1$ is shown in the leftmost panels

b. $\quad 0.35<R_{2010 / 2050}<0.65$ comprises cases where the first 20 -year change is roughly half of the 40 -year change. (linear trend)

c. $R_{2010 / 2050}>0.65$ comprises cases where the first 20 -year change accounts for most, or all, of the 40-year change, as well as the few cases where it is higher than the 40-year change (convex arc - decelerating rate of change)

Line width represents the percentage of members within a particular range of $R$. In the case presented in Fig. 3, simulations of climate evolution similar to members \#10 and \#17 were indeed a minority, but accounted nonetheless for $20 \%$ of the ensemble.

Figure 4 illustrates how the members from the large ensembles are distributed among the three categorizations described above.

A rather linear change $\left(0.35<R_{2010 / 2050}<0.65\right)$ is the most common across all three datasets and indices and accounts for roughly 50 to $100 \%$ of the members for most of the grid cells. The second most common behavior is the "accelerating" ratio $\left(R_{2010 / 2050}<0.35\right)$, whereas the "decelerating" $\left(R_{2010 / 2050}>0.65\right)$ ratio is less common, but still regularly accounts for 5 to $15 \%$ of the members, especially for TX3day and TN3day.

Many of the spatial patterns observed in previous figures are reflected in Fig. 4. Regions that experience higher paces of warming during the 2041-2060 period (average $\alpha_{2050 / 2030} \geq$ 1.2, as per Fig. 2) predominantly display a linear behavior regardless of the index. With the exception of Tmean-CMIP5, grid cells where the "accelerating" ratio accounts for $30 \%$ or more of the large ensemble are mostly located on grid cells that exhibited an average pace of warming $\alpha_{2050 / 2030}$ close to 1 . Clear spatial patterns are less common with the "decelerating" ratio, but seem to be focused on grid cells where the average $\alpha_{2050 / 2030}$ was lower than 1 . This indicates that areas where the climate change signal is weaker have more chance to experience the changes early due to internal variability. This is observed with TX3day-CESM too, where the members located within the hotspot in southeastern USA have a 30 to $40 \%$ chance to have a ratio higher than 0.65 , whereas this region displayed an average $\alpha_{2050 / 2030}$ of 0.2 to 0.4 . On the other hand, regions that exhibit severe climate change signals are more likely to have a linear or "accelerating" behavior, as external forcings are the primary driving factors and internal variability alone cannot account for the change.

For the most part, the spatial patterns in CMIP5 are in accordance with CanESM2-LE and CESM-LE. It can thus be said that the combination of inter-model and internal variability in CMIP5 adequately represents internal variability as portrayed by single-model ensembles. There are still notable differences, such as more members within the " $R_{2010 / 2050}<0.35$ " category for Tmean, as well as a higher number of members where $\alpha_{2050 / 2010}$ is smaller than 1 with TX3day.

Figure 5 illustrates the proportion of members that exhibits severe warming, defined as $\alpha \geq$ $2 \sigma$. The probability for the pace of warming to reach $\alpha \geq 2 \sigma$ remains low across most of the domain and all indices. However, it should be noted that the increase observed in Fig. 5 from $\alpha_{2030 / 2010}$ to $\alpha_{2050 / 2030}$ predominantly originates from members within the "accelerating" category, which were found to be two to five times more likely to have a period of very fast warming during the 2041-2060 period. Indeed, 67 to $70 \%$ of the members with lower-thanmedian temperatures during the 2021-2040 time period, which make up for a majority of the members within the "accelerating" category, end up near or above the median by 2041-2060. 


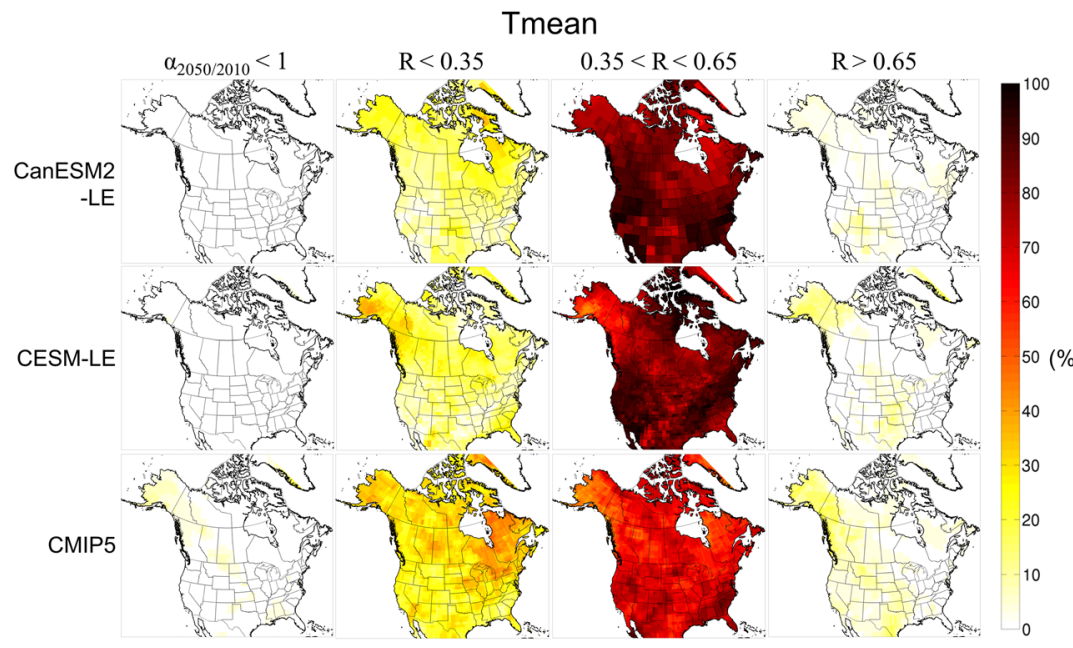

TX3day

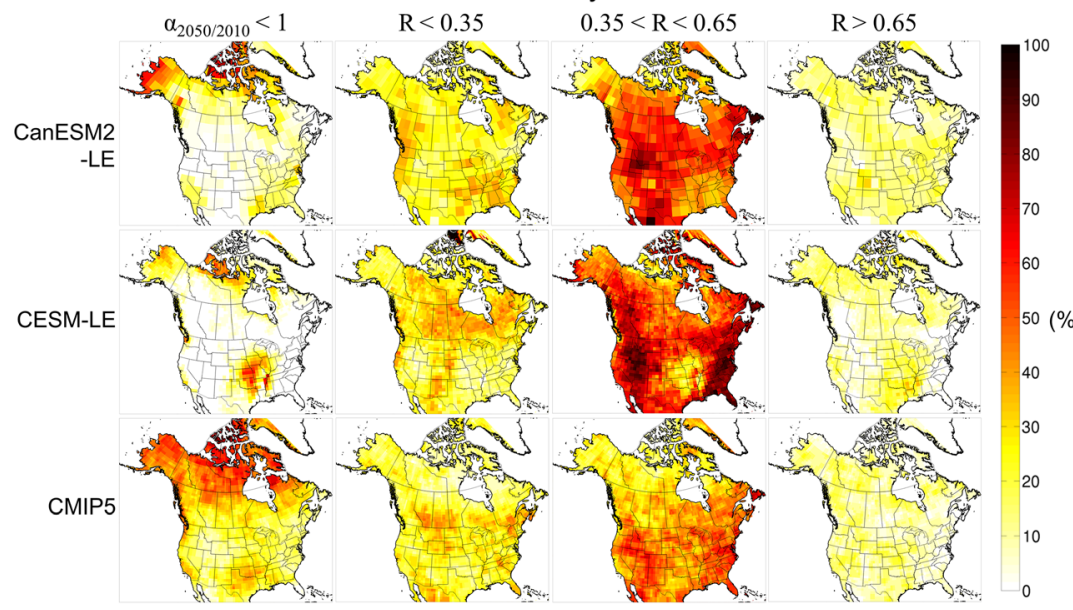

TN3day

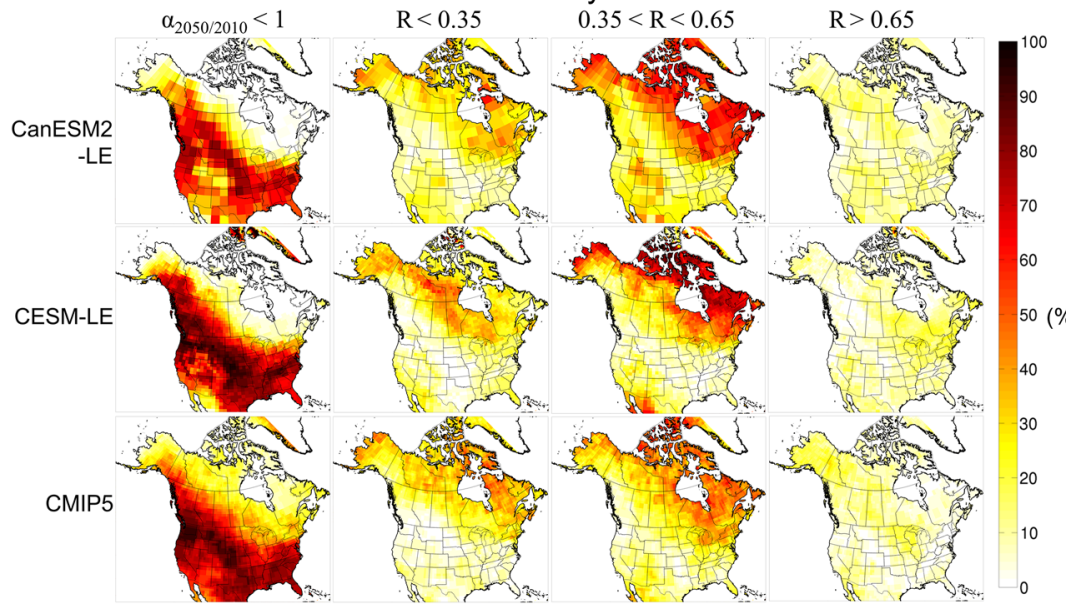




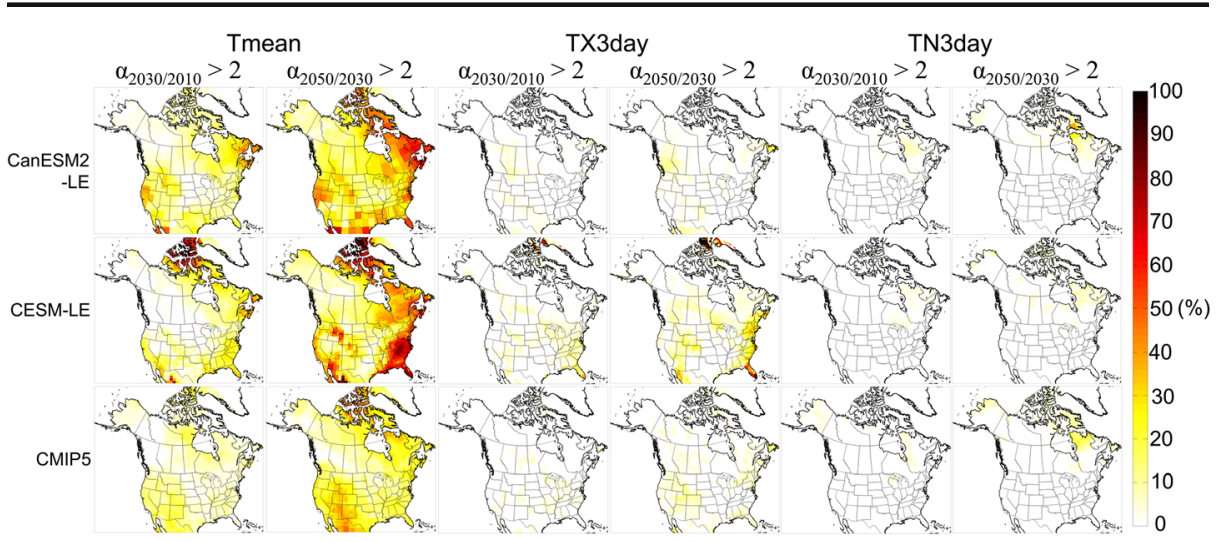

Fig. 5 Probability for large ensemble members to exhibit fast warming, characterized by $\alpha \geq 2 \sigma$

CESM-LE is the dataset that exhibits the highest number of members with $\alpha_{2050 / 2030} \geq 2$, which reflects the model's low interannual variability along the East Coast. The Canadian Arctic also stands out as a region of fast warming. In those two areas, the probabilities of periods of very fast warming can account for up to $50 \%$ of the large ensemble members.

A sensitivity analysis was performed to assess the impact of the starting year of the time periods, by moving the experiment back in time into the historical period. The spatial patterns remain stable, but the absolute values begin to be altered after 5 to 10 years of shifting the time periods away from $R_{2010 / 2050}$ (e.g., $R_{2005 / 2045} ; R_{2000 / 2040}$ ). The probability for a linear change remains the most common, and the probabilities for the "accelerating" and "decelerating" ratios become roughly equal across the domain. This illustrates that when the climate change signal over a period is weaker, IV becomes more dominant and, thus, path of climate evolution becomes less predictable.

On the contrary, for a $R_{2015 / 2055}$ experiment and later, the probability for a fairly linear change becomes progressively higher and reaches nearly $100 \%$ by $R_{2050 / 2090}$ for Tmean. This is also the case for TX3day and TN3day, but to a lesser extent. This can be explained by the fact that as we move forward in the century, the external forcing becomes dominant over internal variability and dictates the increase in temperature. This is in accordance with other studies that pointed to slowdowns, temporary hiatuses, and extremely warm years becoming less common as climate change intensifies (Grenier et al. 2015; Chavaillaz et al. 2016b). This is also reflected by the number of members with $\alpha \geq 2$, which peaks during the 2061-2080 period.

\section{Discussion and Conclusion}

This study explored internal variability within CanESM2-LE and CESM-LE, two singlemodel large ensembles, and compared it with the variability of a CMIP5 ensemble. Three temperature indices were assessed. They consisted of the mean annual temperature (Tmean) and the annual maximum and minimum of the temperature averaged over 3 consecutive days (TX3day and TN3day). These indices were used to study how IV can affect short-term trends of warming by partially masking or accelerating the climate trend. This analysis was done through a signal-to-noise approach and by comparing how individual ensemble members behave between 2001 and 2060 . 
The normalized pace of warming for Tmean is highest along the coasts, characterized by a low interannual variability, and in the Canadian Arctic, where the climate change signal is more pronounced. On the contrary, it is the slowest along a line that follows the eastern side of the Rocky Mountains. For both extreme indices, the higher internal variability means that although temperatures are rising, the average normalized warming often remains below a signal-to-noise ratio of 1 . Some differences have been noted between CanESM2-LE and CESM-LE, but in general, there is a good agreement between both ensembles, which reinforces the results.

The role of an experiment such as CMIP5 is to encompass both the inter-model variability and internal variability, to provide scientifically justifiable signals of climate change. Nonetheless, we found that CMIP5 was often able to produce results, with regard to spatial patterns and variability on the pace of change itself, that were similar to the single-member ensembles. This suggests that CMIP5 models, when grouped together, behave in a way that is similar to large ensembles created specifically to study IV. Differences still exist between CMIP5 and the large ensembles, such as more CMIP5 models having a slower start-up to the warming trends, labeled "accelerating ratio" in this work. This is likely caused by the fact that both CanESM2 and CESM1(CAM5) warm more than the CMIP5 median. Of all the CMIP5 simulations that end up within the "accelerating ratio" category, 50 to $100 \%$ have a temperature change $\Delta T_{2050}$ / 2010 that is under the ensemble median (Online Resource 7). This illustrates a limitation of this study, which is that both large ensembles have high climate sensitivity. A large ensemble with a pace of warming that is slower than the CMIP5 average would be ideal to validate this hypothesis, but such an ensemble did not exist at the time of the study.

Our results indicate that under the RCP8.5, between 2021 and 2060, the increase in mean annual temperature should be roughly linear, with a 60 to $100 \%$ probability across CMIP5 and large ensembles. This is likely one of the better scenarios in terms of adaptation, as it means that solutions can be implemented gradually as the need arises. For the entire domain according to CMIP5, and in some regions such as Canada and Alaska for large ensembles, there is nonetheless a 20 to $35 \%$ probability that the pace of warming over the next 20 years will be small in comparison with the overall trend towards the 2050 horizon. This could be beneficial for adaptation, as it provides a longer timeframe to implement the necessary adaptation measures, but this scenario has the potential danger of making stakeholders underestimate the real magnitude of the upcoming change. Moreover, these scenarios have been found to be more likely to experience fast warming, following the gradual temperature increase between 2021 and 2040. Indeed, 67 to $70 \%$ of the large ensemble members that project lower-than-median temperatures during the 2021-2040 time period end up near or above the median of the ensemble by 2041-2060.

The probabilities for a fast temperature increase in the next 20 years, with most or all of the warming projected for 2050 taking place several years early, are close to nil for most of the study area. In terms of climate change adaptation, this scenario would be likely to be the most damaging to stakeholders. In areas of Alaska and central USA, there is nonetheless a 5 to $15 \%$ probability for such rapid warming to occur for Tmean, and higher for extreme indices.

Due to the nature of GCMs, the indices studied during this analysis could not be directly related to the needs of stakeholders, who require downscaled, local data to assess their vulnerability. Future studies aim to explore how typical downscaling methods used for climate services, such as quantile mapping, could be improved to maintain the internal variability within large ensembles such as CanESM2-LE and CESM-LE. It would also be relevant to 
compare the current likelihood of linear, accelerating, or decelerating rate of change with other large ensembles, ideally with a lower climate sensitivity or another RCP, as such products are becoming more available. Finally, a continuation of this work could be to explore how recent regional model large ensembles, namely CanESM2-CRCM5 (ClimEx; Leduc et al. (2019)) and CanESM2-CanRCM4, compare with the driving model CanESM2-LE.

Acknowledgements We would like to acknowledge the Quebec Ministry of Economy, Science, and Innovation (MESI), as well as its QuébecInnove program. Without them, this research project would not have been possible.

We also acknowledge Environment and Climate Change Canada's Canadian Centre for Climate Modelling and Analysis for producing and making available the CanESM2 Large Ensemble simulations used in this study, and the Canadian Sea Ice and Snow Evolution Network for proposing the simulations. We acknowledge the CESM Large Ensemble Community Project and supercomputing resources provided by NSF/CISL/Yellowstone. Finally, we acknowledge the World Climate Research Programme's Working Group on Coupled Modelling, which is responsible for CMIP, and we thank the climate modeling groups (listed in Online Resource 1) for producing and making available their model output. For CMIP, the U.S. Department of Energy's Program for Climate Model Diagnosis and Intercomparison provides coordinating support and led development of software infrastructure in partnership with the Global Organization for Earth System Science Portals.

We would also like to acknowledge Diane Chaumont for her supervision and guidance.

Open Access This article is distributed under the terms of the Creative Commons Attribution 4.0 International License (http://creativecommons.org/licenses/by/4.0/), which permits unrestricted use, distribution, and reproduction in any medium, provided you give appropriate credit to the original author(s) and the source, provide a link to the Creative Commons license, and indicate if changes were made.

\section{References}

Andrews T, Gregory JM, Webb MJ, Taylor KE (2012) Forcing, feedbacks and climate sensitivity in CMIP5 coupled atmosphere-ocean climate models. Geophys Res Lett 39:1-7. https://doi.org/10.1029/2012 GL051607

Arora VK, Scinocca JF, Boer GJ, Christian JR, Denman KL, Flato GM, Kharin VV, Lee WG, Merryfield WJ (2011) Carbon emission limits required to satisfy future representative concentration pathways of greenhouse gases. Geophys Res Lett 38:3-8. https://doi.org/10.1029/2010GL046270

Bukovsky MS (2011) Masks for the Bukovsky regionalization of North America. Regional Integrated Sciences Collective, Institute for Mathematics Applied to geosciences, National Center for Atmospheric Research, Boulder http://www.narccap.ucar.edu/contrib/bukovsky/. Accessed 2016-11-04

Chavaillaz Y, Joussaume S, Bony S, Braconnot P (2016a) Spatial stabilization and intensification of moistening and drying rate patterns under future climate change. Clim Dyn 47:951-965. https://doi.org/10.1007/s00382015-2882-9

Chavaillaz Y, Joussaume S, Dehecq A, Braconnot P, Vautard R (2016b) Investigating the pace of temperature change and its implications over the twenty-first century. Clim Chang 137:187-200. https://doi.org/10.1007 /s10584-016-1659-4

Collins M, Knutti R, Arblaster J, Dufresne J-L, Fichefet T, Friedlingstein P, Gao X, Gutowski WJ, Johns T, Krinner G, Shongwe M, Tebaldi C, Weaver AJ, Wehner M (2013) Long-term climate change: projections, commitments and irreversibility. Climate Change 2013: The Physical Science Basis. Contribution of Working Group I to the Fifth Assessment Report of the Intergovernmental Panel on Climate Change 1029-1136

de Elía R, Biner S, Frigon A (2013) Interannual variability and expected regional climate change over North America. Clim Dyn 41:1245-1267

de Elía R, Biner S, Frigon A, Côté H (2014) Timescales associated with climate change and their relevance in adaptation strategies. Clim Chang 126:93-106

Deser C, Phillips AS, Alexander MA, Smoliak BV (2014) Projecting North American climate over the next 50 years: uncertainty due to internal variability. J Clim 27:2271-2296

Fyfe JC, Meehl GA, England MH, Mann ME, Santer BD, Flato GM, Hawkins E, Gillett NP, Xie S-P, Kosaka Y, Swart NC (2016) Making sense of the early-2000 global warming slowdown. Nat Clim Chang 6:224-228 
Gastineau G, García-Serrano J, Frankignoul C (2017) The influence of autumnal Eurasian snow cover on climate and its link with Arctic sea ice cover. J Clim 30:7599-7619. https://doi.org/10.1175/JCLI-D-16-0623.1

Giorgi F, Bi X (2009) Time of emergence (TOE) of GHG-forced precipitation change hot-spots. Geophys Res Lett 36:1-6. https://doi.org/10.1029/2009GL037593

Grenier P, De Elía R, Chaumont D (2015) Chances of short-term cooling estimated from a selection of CMIP5based climate scenarios during 2006-35 over Canada. J Clim 28:3232-3249. https://doi.org/10.1175/JCLID-14-00224.1

Guirguis K, Gershunov A, Tardy A, Basu R (2014) The impact of recent heat waves on human health in California. J Appl Meteorol Climatol 53:3-19. https://doi.org/10.1175/JAMC-D-13-0130.1

Hawkins E (2011) Our evolving climate: communicating the effects of climate variability. Weather 66:175-179

Hawkins E, Sutton R (2009) The potential to narrow uncertainty in regional climate predictions. Bull Am Meteorol Soc 90:1095-1107

Hawkins E, Sutton R (2012) Time of emergence of climate signals. Geophys Res Lett 39:1-6

Hurrell JW, Holland MM, Gent PR, Ghan S, Kay JE, Kushner PJ, Lamarque JF, Large WG, Lawrence D, Lindsay K, Lipscomb WH, Long MC, Mahowald N, Marsh DR, Neale RB, Rasch P, Vavrus S, Vertenstein M, Bader D, Collins WD, Hack JJ, Kiehl J, Marshall S (2013) The community earth system model: a framework for collaborative research. Bull Am Meteorol Soc 94:1339-1360. https://doi.org/10.1175 /BAMS-D-12-00121.1

Kay JE, Deser C, Phillips A, Mai A, Hannay C, Strand G, Arblaster JM, Bates SC, Danabasoglu G, Edwards J, Holland M, Kushner P, Lamarque JF, Lawrence D, Lindsay K, Middleton A, Munoz E, Neale R, Oleson K, Polvani L, Vertenstein M (2015) The community earth system model (CESM) large ensemble project : a community resource for studying climate change in the presence of internal climate variability. Bull Am Meteorol Soc 96:1333-1349. https://doi.org/10.1175/BAMS-D-13-00255.1

Klein RJT, Midgley GF, Preston BL, Alam M, Berkhout FGH, Dow K, Shaw MR (2014) Adaptation opportunities, constraints, and limits. Assessment Report 5- Climate Change 2014: Impacts, Adaptation, and Vulnerability Part A: Global and Sectoral Aspects 899-943. https://doi.org/10.1017 /CBO9780511807756.003

Koster RD, Dirmeyer PA, Guo Z, Bonan G, Chan E, Cox P, Gordon CT, Kanae S, Kowalczyk E, Lawrence D, Liu P, Lu C-H, Malyshev S, McAvaney B, Mitchell K, Mocko D, Oki T, Oleson K, Pitman A, Sud YC, Taylor CM, Verseghy D, Vasic R, Xue Y, Yamada T (2004) Regions of strong coupling between soil moisture and precipitation. Science 305:1138-1140. https://doi.org/10.1126/science.1100217

Kushner PJ, Mudryk LR, Merryfield W, Ambadan JT, Berg A, Bichet A, Brown R, Derksen CP, Dery SJ, Dirkson A, Flato G, Fletcher C, Fyfe J, Gillett N, Haas C, Howell S, Laliberte F, McCusker K, Sigmond M, Sospedra-Alfonso R, Tandon NF, Thackeray C, Tremblay B, Zwiers FW (2017) Assessment of snow, sea ice, and related climate processess in Canada's earth system models and climate prediction systems. The cryosphere discussions 1-34

Leduc M, Mailhot A, Frigon A, Martel J-L, Ludwig R, Brietzke GB, Giguére M, Brissette F, Turcotte R, Braun M, Scinocca J (2019) ClimEx project: a 50-member ensemble of climate change projections at 12-km resolution over Europe and northeastern North America with the Canadian Regional Climate Model (CRCM5). J Appl Meteorol Climatol:663-693. https://doi.org/10.1175/jamc-d-18-0021.1

Lehner F, Deser C, Terray L (2017) Toward a new estimate of "time of emergence" of anthropogenic warming: insights from dynamical adjustment and a large initial-condition model ensemble. J Clim 30:7739-7756. https://doi.org/10.1175/JCLI-D-16-0792.1

Liebmann B, Dole RM, Jones C, Bladé I, Allured D (2010) Influence of choice of time period on global surface temperature trends estimates. Bull Am Meteorol Soc 1485-1491. https://doi.org/10.1175/2010BAMS3030.1

Lin $\mathrm{H}$, Wu Z (2011) Contribution of the autumn Tibetan plateau snow cover to seasonal prediction of North American winter temperature. J Clim 24:2801-2813. https://doi.org/10.1175/2010JCLI3889.1

McKinnon KA, Poppick A, Dunn-Sigouin E, Deser C (2017) An "observational large ensemble" to compare observed and modeled temperature trend uncertainty due to internal variability. J Clim 30:7585-7598. https://doi.org/10.1175/JCLI-D-16-0905.1

Meehl G, Tebaldi C (2004) More intense, more frequent, and longer lasting heat waves in the 21st century. Science 305:994-997. https://doi.org/10.1126/science.1098704

Meehl GA, Stocker TF, Collins WD, Friedlingstein P, Gaye AT, Gregory JM, Kitoh A, Knutti R, Murphy JM, Noda A, Raper SCB, Watterson IG, Weaver AJ, Zhao Z-C (2007) Global Climate Projections. Climate Change 2007: contribution of Working Group I to the Fourth Assessment Report of the Intergovernmental Panel on Climate Change 747-846. https://doi.org/10.1080/07341510601092191

Meehl GA, Arblaster JM, Fasullo JT, Hu A, Trenberth KE (2011) Model-based evidence of deep-ocean heat uptake during surface-temperature hiatus periods. Nat Clim Chang 1:360-364. https://doi.org/10.1038 /nclimate1229 
Meehl GA, Washington WM, Arblaster JM, Hu A, Teng H, Kay JE, Gettelman A, Lawrence DM, Sanderson BM, Strand WG (2013) Climate change projections in CESM1(CAM5) compared to CCSM4. J Clim 26: 6287-6308. https://doi.org/10.1175/JCLI-D-12-00572.1

Merrifield A, Lehner F, Xie SP, Deser C (2017) Removing circulation effects to assess central U.S. landatmosphere interactions in the CESM large ensemble. Geophys Res Lett 44:9938-9946. https://oi. org/10.1002/2017GL074831

Moore FC, Obradovich N, Lehner F, Baylis P (2019) Rapidly declining remarkability of temperature anomalies may obscure public perception of climate change. Proc Natl Acad Sci 116:4905 LP-4904910. https://doi. org/10.1073/pnas.1816541116

Mote TL, Kutney ER (2012) Regions of autumn Eurasian snow cover and associations with North American winter temperatures. Int J Climatol 32:1164-1177. https://doi.org/10.1002/joc.2341

Mudryk LR, Derksen C, Howell S, Laliberté F, Thackeray C, Sospedra-Alfonso R, Vionnet V, Kushner PJ, Brown R (2018) Canadian snow and sea ice: historical trends and projections. Cryosphere 12:1157-1176. https://doi.org/10.5194/tc-12-1157-2018

Seneviratne SI, Wilhelm M, Stanelle T, Van Den Hurk B, Hagemann S, Berg A, Cheruy F, Higgins ME, Meier A, Brovkin V, Claussen M, Ducharne A, Dufresne JL, Findell KL, Ghattas J, Lawrence DM, Malyshev S, Rummukainen M, Smith B (2013) Impact of soil moisture-climate feedbacks on CMIP5 projections: first results from the GLACE-CMIP5 experiment. Geophys Res Lett 40:5212-5217

Settele J, Scholes RJ, Betts RA, Bunn S, Leadley P, Nepstad D, Overpeck JT, Toboada MA (2014) Terrestrial and inland water systems. Climate Change 2014: Impacts, Adaptation, and Vulnerability Part A: Global and Sectoral Aspects Contribution of Working Group II to the Fifth Assessment Report of the Intergovernmental Panel on Climate Change 271-359

Seviour WJM (2017) Weakening and shift of the Arctic stratospheric polar vortex: internal variability or forced response? Geophys Res Lett 44:3365-3373. https://doi.org/10.1002/2017GL073071

Sheffield J, Camargo SJ, Fu R, Hu Q, Jiang X, Johnson N, Karnauskas KB, Kim ST, Kinter J, Kumar S, Langenbrunner B, Maloney E, Mariotti A, Meyerson JE, Neelin JD, Nigam S, Pan Z, Ruiz-Barradas A, Seager R, Serra YL, Sun DZ, Wang C, Xie SP, Yu JY, Zhang T, Zhao M (2013) North American climate in CMIP5 experiments. Part II: Evaluation of historical simulations of intraseasonal to decadal variability. J Clim 26:9247-9290. https://doi.org/10.1175/JCLI-D-12-00593.1

Sigmond M, Fyfe JC (2016) Tropical Pacific impacts on cooling North American winters. Nat Clim Chang 1-22

Taylor KE, Stouffer RJ, Meehl GA (2011) An overview of CMIP5 and the experiment design. Bull Am Meteorol Soc 93:485-498

Thornton PE, Thornton MM, Mayer BW, Wei Y, Devarakonda R, Vose RS, Cook RB (2016) Daymet: daily surface weather data on a 1-km grid for North America, version 3. ORNL DAAC, Oak Ridge, Tennessee, USA. https://doi.org/10.3334/ORNLDAAC/1328

van Vuuren DP, Edmonds J, Kainuma M, Riahi K, Thomson A, Hibbard K, Hurtt GC, Kram T, Krey V, Lamarque JF, Masui T, Meinshausen M, Nakicenovic N, Smith SJ, Rose SK (2011) The representative concentration pathways: an overview. Clim Chang 109:5-31. https://doi.org/10.1007/s10584-011-0148-Z

von Salzen K, Scinocca JF, McFarlane NA, Li J, JNS C, Plummer D, Verseghy D, Reader MC, Ma X, Lazare M, Solheim L (2013) The Canadian fourth generation atmospheric global climate model (CanAM4). Part I: Representation of Physical Processes. Atmosphere-Ocean 51:104-125. https://doi.org/10.1080 $/ 07055900.2012 .755610$

Publisher's note Springer Nature remains neutral with regard to jurisdictional claims in published maps and institutional affiliations. 